Est Ag 44 (2009) 199-209

\title{
Nuevos lenguajes teológicos centrados en la Creación.
} Novedad y continuidad

"El Dios de los cristianos me parece demasiado pequeño para tanta maravilla que encierra el mundo" (Adriana, en Berlín, junto al lago que circunda a Kladow).

No fueron previstas las consecuencias de aquel número primero de la Gaudium et Spes: "Los gozos y las esperanzas, las tristezas y las angustias de los hombres de nuestro tiempo, sobre todo de los pobres y de cuantos sufren, son a la vez gozos y esperanzas, tristezas y angustias de los discípulos de Cristo. Nada hay verdaderamente humano que no encuentre eco en su corazón" (GS, 1). Era como encender una luz o abrir una ventana después de un largo tiempo de represión tras largos años de pretender ir contra la corriente. La Iglesia había llegado, pero demasiado tarde (Doudon Diène: $675 \mathrm{ss}$ ). Comenzaba una lectura laica de la historia que la elevaba a la dignidad de una y sola historia de salvación. Venía a ser la solución a una serie de reivindicaciones religiosas, estrechamente ligadas a las formas como se ha expandido el colonialismo occidental de origen grecorromano por el resto de los países del mundo considerados menores, subdesarrollados o en vías de desarrollo.

David J. Bosch (Bosch: 230), recogiendo la teoría de Hans Küng (Küng: 77), ha dividido las etapas del cristianismo en seis paradigmas, que en su momento exigieron cambios profundos, aunque siempre bajo la influencia de la cultura dominante. Hoy hemos llegado al paradigma del ecumenismo que requiere cambios en las relaciones misioneras con las alternativas de expresión religiosa y los sujetos de la influencia que ejercen sobre el imaginario mundial los descubrimientos de la ciencia y la tecnología, a través de diversos lenguajes.

De hecho, los últimos descubrimientos de las ciencias lingüísticas y de los sistemas de la semiótica, han venido a demostrar que el mejor método 
para marcar una distancia etnocida y excluyente sobre grupos diferentes (Lotman: 93) es el de hacerles entender que su lengua es de ningún valor. En la lengua dominante predomina una secreta voluntad de eliminar lo otro para imponer lo que considera único y exclusivo, es decir, lo nuestro, lo propio de quienes practicamos la única forma verdadera de seguir al Dios de Jesucristo. Las formas como han sido destruidas sistemáticamente (aunque sin el éxito esperado) las religiones andinas (Kauffmann: 2) y otras religiones animistas menores ha partido del desencuentro en los lenguajes de los nuevos paradigmas. Son los elementos que privan a la Iglesia de asumir en su encerramiento ideológico occidental otras formas de ser y pensar(Ibid.: 3). El concepto de misión lleva consigo, pues, una implícita actitud racista, que niega la capacidad y responsabilidad del otro, y tiende a debilitar su espiritualidad.

La transformación de las lenguas en el tiempo ha sido una señal inequívoca de la transformación en el sistema de valores, de los cambios culturales e ideológicos que se han producido al interior de los pueblos. De este modo asistimos a una acelerada transformación semiológica, expresión del cambio en distintos lenguajes o estructuras internas en los campos éticos y culturales (Doudu Diène: 685).

\subsection{Lenguaje y represión}

Todo lenguaje lleva dentro de sí un pensamiento, una estructura cultural del mundo en que se ha elaborado. La fijación de las abstracciones hace que el lenguaje vaya perdiendo sentido, hayan cegado a la institución eclesiástica y no hayan permitido abrir los ojos a las evidencias (González Faus: $9 \mathrm{ss}$ ): ni religiones (Gellman y Hartman: 69 ss), ni inculturación, ni avances científicos, ni sus correlatos en el pensamiento de la pos-modernidad, ni desarrollo inductivo de las iglesias locales, ni, incluso, las formas teológicas de pensar dentro de la misma fe de Jesús. Todo ha tratado de homogeneizarse, uniformizarse sin respeto a las diferencias (Morin: I, 171) ni a los modos como el Dios creador actúa al interior de la materia, de la vida, del universo. El conservadurismo en la salvaguarda de la "tuta doctrina" nos ha - hecho olvidar la diversidad teológica de los tiempos evangélicos, de la literatura patrística y de las tradiciones teológicas orientales y occidentales.

En tales circunstancias la fusión entre Iglesia y Estado viene a ser un metalenguaje que convierte el discurso de la teología en una necesidad más profunda que la misma fe y se convierte en una prevalencia hegemónica de la cultura grecorromana que se ha venido transmitiendo desde antes del 
Cristianismo. En términos de política se traduce en una fuerza para defender las propias ideas sin dejarse penetrar de las de los demás y en una conjunción de la Cruz y la espada.

\subsection{Diálogo e interacción}

Hace algún tiempo la ONU declaró el Año de la Tolerancia como método pedagógico para aprender a respetar al otro, para dejar que el diferente se moviera en su campo sin que penetrase en el mío. El diálogo sin embargo supone un paso más, la intercomunicación entre distintos modos de pensar y de ver, pero sin más compromiso que el conocimiento recíproco. Hay un tercer nivel: la interacción nos lleva no solamente a valorar la riqueza del otro, sino a entrar en un proceso de interactuación, que nos abre a los lenguajes del otro y deja que transformen los nuestros en función a un sentido y nivel superior. La forma suprema del encuentro está en lograr los lenguajes comunes, en llegar a una síntesis nueva y transfiguradora. Desde la creación del mundo, de la explosión del Big-Ban, han comenzado a evolucionar el mundo y la vida desde el primer nitrógeno, hidrógeno, oxígeno y azufre, hasta formar la primera bacteria cuya existencia se convirtió en permanente después de múltiples derrotas en la lucha por la aparición de la vida. Sobrevivió gracias a dos elementos vitales: el ADN para reproducirse y la rapidez con que lo hacía. Lo uno y lo complejo son dos caras de la misma moneda.

\subsection{Lo uno y lo complejo}

Si hay algo en lo que tenemos que cambiar hasta de piel, en hacer una metanoia, es en nuestro modo de enfrentar la diversidad, que ciertamente reconocemos existe, pero que no somos capaces de gerenciar (García: Cultura Amazónica y Educación Intercultural: 6). Lo uno y lo complejo se nos hace más visible. La biología organicista, la sicología de la gestalt, la ecología, la física cuántica y la física nuclear han producido una transformación revolucionaria. La evolución de la vida y las formas como la investigación genética, los descubrimientos del $\mathrm{ADN}$ y el $\mathrm{ARN}$, base del código genético nos abren a mundos que no imaginábamos. El pensamiento ya no parte de filósofos ni teólogos: son los científicos quienes dan sentido a la nueva manera de pensar el mundo (Capra: 25; Guiton: 11). Todo tiene su sentido, tiene derecho a ser diferente: nada de cuanto existe es semejante ni siquiera parecido a la individualidad. Pero, al mismo tiempo, todo es unitario, 
desde las primeras partículas. Después de los estudios de Max Planck y Einstein, hasta la complejidad del cerebro humano tiene inequívocos lenguajes. No en vano las gentes sencillas cuidan las plantas transmitiéndolas lenguajes humanos del alma, de equilibrio interior. $\mathrm{O}$ se difunde en el ambiente música barroca para que fluya la leche del ganado. Los ciclos de la naturaleza han sido perturbados a partir de las teorías cartesiano-baconianas que elevaron exponencialmente su fuerza de producción, distanciándolos de los modelos naturales. Hoy sabemos que existe un billón de interconexiones entre las neuronas del cerebro que solamente se realizan a través de lenguajes. Los sistemas de soporte electrónico, imitándoles, se basan en los lenguajes con que se alimentan

La Creación, por otra parte, no puede ser entendida sin el Verbo (Jn 1, 1) como algo que impregna de energía todo lo viviente. Me van a permitir exponga mi punto de vista: si la Palabra llena el universo, si nada de cuanto existe está fuera de ella, hemos de reconocer que todas las religiones míticas africanas o amazónicas o mesoamericanas tienen un sentido místico profundo y son espacios de resistencia a cualquier interferencia política, de las colonizaciones tanto de la antigüedad como del siglo XIX. Las formas religiosas originarias no mueren, se transforman, asumen de una manera determinada el entorno, e interpretan lo que les acontece desde sus propios lenguajes, sus claves, a pesar de que hayan cambiado las formas y rituales, como en el caso de los sufíes (Doudu Diène: 681).

\section{Nuevas teologías: nuevos lenguajes}

Torres Queiruga afirma que "son muchas las verdades que los cristianos afirmamos sin acabar de creérnoslas" (Torres Queiruga: 17). Y sigue preguntándose sobre las relaciones con un Dios implacable y justo comparándolas con nuestra experiencia humana de ternura, de esperanza y de paz. Las metáforas antropomórficas justicieras se vienen abajo. Estamos abriendo caminos para que los cristianos pierdan en occidente el sentido de la fe, y pasen por una situación de descrédito, de desencanto institucional. Se calcula que cada día abandonan las Iglesias cristianas más de cincuenta mil fieles. Paradójicamente lo religioso está tomando nuevo impulso en el mundo y se ha convertido en fundamental para la interpretación de cualquier sociedad. En una primera etapa, se van enfriando y distanciando de la institucionalidad eclesial: les parece algo obsoleto y fuera de sentido (García: La Misión testimonio de la Creación: 21). "Me pregunto a este propósito cuando se vayan cayendo los fundamentalismos científicos de nuestras creencias: alma 
y cuerpo, cielo y tierra, dónde van nuestras cenizas, si habrá o no otros mundos como el nuestro, cuál es el alma de los animales, que sucederá si se logra reproducir el ser humano, cuáles serán las condiciones para la bioética en el siglo XXI" (García: Inculturación...: 117). Podemos concluir que los lenguajes de la teología y de la misionología o cualquier otra disciplina eclesial han variado esencialmente poco, $y$ han sido poco fieles a la verdad.

\section{Nuevos lenguajes desde la Creación}

Un tumor en el cerebro hizo que me abriera a los nuevos lenguajes de la ciencia: me reconcilié con la materia. Hasta en la última partícula, en el último de los fragmentos de los átomos entendí que vibraba la vida, que de la materia procedían todos y cada uno de mis órganos, que todo era viviente. Mil millones de neuronas, interconectadas en una red de un billón de sinapsis... Todo ello en patrones intrincados de tramas interconectadas, redes animando el seno de redes mayores (Capra: 100). Comprobé que la distancia del mundo de la ciencia y el de la fe, a pesar de los saltos cualitativos del Concilio Vaticano II, era inconmensurable. Me persuadí que no había más que una y sola historia salvífica, y que la fuerza de Dios había de ser hallada en la vida que Él siembra en todo ser que viene a este mundo. Elaborar lenguajes inéditos es como una aventura, como acercarse a la realidad desde la que Dios habla, ser contemplativos e interpelados por su fuerza.

La fuerza de Dios está en el hombre y su entorno. Es la expresión acabada de la Creación y, por lo mismo, tiene derecho a un lenguaje que surge desde aquel interior, con que nós sentimos solidarios.

Daniel Dennett (Dennett: 39) adelanta en un trabajo publicado en la revista Science la posibilidad de que exista incluso un área de la masa encefálica destinada a lo religioso, y que sería la razón de que nunca como ahora se hayan convertido en religiosos los movimientos políticos más fanáticos. Descubrir esos códigos, dejar que se desarrollen, intercomunicarnos con ellos es el camino mejor para descubrir las riquezas de la Creación y ser una forma de vida religiosa comunional.

\section{Nuevos lenguajes desde la ciencia}

Completé mi experiencia con aportes más conceptuales de los avances de la ciencia y la genética. Antonio Damasio publicó a mitad de la década 
de los noventa "El error de Descartes", donde adelantaba una propuesta diferente a lo que pudo haber pensado el filósofo francés del siglo XVII. Distribuía las diferentes zonas del cerebro y demostraba cómo algunas de ellas afectaban a dimensiones hasta ahora consideradas espirituales en el sentido tradicional. “... El pensamiento lineal, lógico y matemático del autor de La duda metódica había sido superado por los avances científicos nucleares, que aportaban nuevas comprensiones de las redes biológicas y genéticas entre las células y sus componentes. La claridad y evidencia de este pensamiento hacían poner en duda mi comprensión tradicional de las formas de inserción del alma espiritual en los tejidos de la carne de mi cuerpo. Aprendí con Teilhard de Chardin que estaba formado de una materia que entretejía mi corazón, su sensibilidad, su energía: que todo en mí procedía del Dios Viviente y Creador; que era el resultado de la evolución de aquella primera masa informe que se expresaba en el hombre como inteligencia cósmica "(García: La Misión...: 22).

Christian de Duve, Premio Nobel de Biología, en 1999 publicaría una síntesis sobre el proceso de la vida titulado "Polvo Vital. El origen y la evolución de la vida en la tierra". Desarrollaba didácticamente la sucesión de los seres vivientes desde el comienzo original de la materia primera. "Me parecía, nos dice, que la ciencia, dada su insistencia en la racionalidad y objetividad, ofrecía el mejor camino para llegar a la verdad, y el estudio de la vida parecía especialmente prometedor. La ciencia iba a ser mi camino hacia la verdad: per vivum ad verum" (De Duve: 17). El libro conduce a través de siete eras consecutivas correspondientes a siete niveles de complejidad: la edad de la química, de la información, de la protocélula, de las células aisladas, de los organismos multicelulares, de la mente y, para retar nuestros conocimientos, la edad de lo desconocido, que incluye el futuro y la eternidad (De Duve: 19).

En el 2002 Llinás, un neurólogo colombiano, publicó "El cerebro y el mito del Yo. El papel de las neuronas en el pensamiento y en el comportamiento humanos". Se adentra en la interioridad del cerebro humano y sus capacidades. Para él la capacidad de predicción es la función primordial del cerebro, hasta el punto de que podría decirse que "el sí mismo" es el centro de la predicción (Llinás: 129 ss). Es decir, no solamente las dimensiones espirituales han de ser reinterpretadas, sino que la espiritualidad de la materia sobrepasa todo lo imaginable, ya que pertenecemos a un cosmos viviente (García: Del mundo interior... 4). San Agustín lo expresa así: "Los gritos de las criaturas son evidencias de Dios" (Sermón 313).

Por otra parte hemos de comprender la caducidad del tiempo que fluye como diría el sabio griego. La realidad en sí no existe: depende solamente del modo como aceptemos observarla. Las entidades elementales que la compo- 
nen pueden ser, al mismo tiempo, una cosa (una onda) y otra (una partícula), y en cualquier caso su realidad es indeterminada. "Llegar al límite de esta oscilación, la frontera de lo divisible, significa acercarnos a la realidad de un ser trascendente, que a la vez es causa y sentido del universo y que nos lleva al metarrealismo, donde acaba la frontera del fraccionamiento y nos sitúa frente a un límite espiritual más cerca de Dios" (García: La Misión...:25).

La resistencia de la Iglesia a la ciencia desde el Renacimiento, a la Ilustración y a la pos-modernidad han hecho que con criterios de conocimiento esclerosados pretendamos comprender la diversidad de significados para una nueva manera de entender el mundo y una bioética que es el resultado de un arcoiris de lenguajes.

\section{5. ¿Cómo deben ser los lenguajes actuales de la teología?}

Ha de pasar mucho tiempo. Nuestra condición cognitiva de sentirnos solos, únicos, exclusivos, es el mayor de los bloqueos al cambio. Recuerdo que, atravesando la Plaza de San Pedro, con cuatro amigos, se me ocurrió comprobar con cuántos brazos podríamos abarcar una columna. Se necesitaban cinco para rodear a aquella mole de piedra. Alguien comentó: "Imagínense cuánto tiempo habrá de transcurrir para que la Iglesia comience a sentirse una con los otros". Lo más difícil es asumir el problema de la diversidad cuando sabemos que "somos los mejores" y que, por lo tanto, solamente debemos cambiar las formalidades exteriores, es decir, adaptarnos para lograr estratégicamente que los demás vengan al redil. Harto complicado que la teología de las verdades abstractas llegue a ceder en aquello que considera su logro, perdida en la nebulosa de lo irreal. Le falta una confianza mayor en el mundo que Dios ha creado y para el que no quiere más que el bien y la vida (Jn 10,10).

Ante tanta incertidumbre, podríamos dejar algunas pistas:

Han cambiado las lenguas, mas no los lenguajes. Es decir, los códigos profundos en que están marcados los arquetipos del inconsciente colectivo (¿y genético?) en su raíz más diferente siguen imperturbables.

La significación solamente es comprensible en una dimensión de semiosfera (Lotman: II, 93). Cualquier otra forma de encuentro es superficial e insuficiente para establecer un diálogo que nos lleve a niveles de avance hacia nuevas formas de interacción y de conciencia.

La captación de un lenguaje distinto tiene una clave fundamental: la inculturación, es decir, la construcción de la Iglesia y, por lo tanto, de la teo- 
logía desde lo local y contextual, desde el otro, desde sus claves de pensamiento, desde sus procesos de interacción. El Primer Encuentro de Misiones en el Alto Amazonas, celebrado en Iquitos en 1971, concluyó que la Iglesia se convertía en amazónica en su teología, en sus estructuras y en su organización. Aquello que se dijo apenas concluía el Concilio, ha quedado desvanecido en el vacío. La mera adaptación no incluye la transformación de la propia teología, ni la concesión del uso de algunos elementos propios de la otra cultura, ni da por supuesto que el problema es de iglesias jóvenes, o de una condición periférica, es decir, habla de forma mas no de contenido. En estos procesos de acomodación se da por supuesto que las iglesias más jóvenes reciben en una sola direcçión la influencia de las más antiguas, que dan a manos llenas a las jóvenes entusiasmo, sangre y abundancia de bienes. Las iniciativas de adaptación no provienen de los recientemente convertidos, sino de misioneros románticos en las culturas exóticas, que insisten en reconocer la "alteridad" de las iglesias nuevas. La semilla era el Evangelio en su formulación occidental: "La cizaña eran los ingredientes culturales diversos" (García, Inculturación...119).

En esta perspectiva debemos considerar el método a través del cual entablamos un diálogo interactivo entre propuestas y religiones diferentes. "La "cultura propia" es considerada como la única. A ella se opone la "no cultura" de las otras colectividades. De esa índole será la relación del griego con el bárbaro, al igual que todas las otras especies de contraposición de una colectividad elegida a una profana... Desde el punto de vista de la cultura que se toma como norma y cuyo lenguaje deviene en metalenguaje de una tipología dada de la cultura, los sistemas que se oponen a ella se yerguen ante ella no como otros tipos de organización, sino como no-organizaciones" (Lotman: II, 93).

Consecuentes con los postulados conciliares, hemos de admitir que necesitamos salir de nuestros lenguajes iniciáticos, laicizar, desacralizar las formas de presentación de nuestras disciplinas, tanto en las relaciones con otras confesiones religiosas, incluyendo la docencia misionológica "ad gentes", como en las disciplinas macro y microcósmicas, y en las infinitas posibilidades de la genética, que en realidad están más cerca de la permanente evolución creadora del mundo que lo que nosotros podamos hacer en nuestras limitadas especulaciones teológicas. El problema es de comunicación profunda: alcanzar la esencia de una cultura o metalenguaje más allá de la lengua y las formas rituales folklóricas.

Los lenguajes de otras religiones están más próximos de lo que pudiéramos pensar si abordamos los temas que preocupan existencialmente a la humanidad. En lo científico y popular debemos aprender a estar atentos a 
las transformaciones que se producen en la mente del mundo (interpretar los "signos de los tiempos"), que afectan a los cambios de las culturas humanas. Tarea difícil, pero hay que emprenderla y en cambios acelerados que marchan al ritmo de la historia desde adentro de pueblos y sistemas que abren el mundo hacia el futuro.

Intuir por dónde va el sentido de la historia, cuál es el trasfondo de la diversidad de religiones que pueblan la tierra, encontrar los puntos de coincidencia y empujar la marcha de la vida en busca de su plenitud es el único camino.

"Para mí, este sentido debe encontrarse en la estructura del universo, constituido de tal forma que produce el pensamiento a través de la vida y de la mente. El pensamiento a su vez es una facultad mediante la cual el universo puede reflejarse a sí mismo, descubrir su propia estructura, y comprender entidades tan inmanentes como la verdad, la belleza, la bondad y el amor. Tal es el significado del universo tal como yo lo veo" (De Duve: 481). J.G.

P. JoAQuín GARCía, OSA. CETA-Iquitos (Perú). II Congreso Mundial de la IACM. Cochabamba (Bolivia) 29. 9 a 4. 10.

\section{OBRAS CONSULTADAS}

Aguilar Sahagún, Guillermo, Cruz JimÉnez, S. y Flores Valdés, J. 1997. Una ojeada a la materia. México: Fondo de Cultura Económica.

ATIENZA, Juan G. 2000. Los pecados de la Iglesia: memoria de una ambición. Barcelona: Juan G. Atienza/Martínez Roca.

BETTO, Fray. 1995. A obra do artista. Uma visão holística do Universo. São Paulo: Atica.

BLÁzQUEZ, Niceto. 2000. Bioética: La nueva ciencia de la vida. Madrid: Biblioteca de Autores Cristianos.

BofF, Leonardo. 1995. Ecologia: Grito da terra, grito dos pobres. Sao Paulo: Atica. -, Leonardo. 2003. La voz del arco iris: Madrid: Trotta.

Bosch, David J. 2000. Misión en transformación: cambios de paradigma en la teología de la misión. Grand Rapids (EE.UU.): Libros Desafío. 
CAPRA, Fritjof. 1999. La trama de la vida: Una nueva perspectiva de los sistemas vivos. Barcelona: Anagrama.

ClARO, Francisco. 1999. A la sombra del asombro: El mundo visto por la física. Santiago de Chile: Andrés Bello.

Concilio VATICANo II. 1966. Constituciones. Decretos. Declaraciones. Segunda Edición. Madrid: Biblioteca de Autores Cristianos (BAC)

DAMASIO, Antonio R. 1996. El error de Descartes: La razón de las emociones. Santiago de Chile: Andrés Bello.

-, Antonio. 2000. Sentir lo que sucede. Cuerpo y emoción en la fábrica de la consciencia. Santiago de Chile. Andrés Bello.

DENNETT, Daniel C. "Appraising grace. What evolutionary good is God? ", en The Sciences. Jan-feb. 1997.

DiCCIONARIO DE CIENCIAS. 2000. Madrid: Complutense.

Duve, Christian de. 1999. Polvo vital: El origen y evolución de la vida en la tierra. Santafé de Bogotá: Norma.

GARCÍA SÁNCHEZ, Joaquín. 1997. Del tiempo interior al cosmos viviente. Promanuscrito.

-, 2001. Medio ambiente y cultura de paz. Promanuscrito.

-, "La misión testimonio de la Creación", en Vida Nueva. N. 2.405, dic. 2003.

-, 2004. Cultura amazónica y educación intercultural. Promanuscrito.

Gellman, Marc y Thomas HARTMAn. 2003. Religión. Bogotá: Grupo Editorial Norma.

GonZÁleZ FAus, José Ignacio.1996. La autoridad de la verdad. Momentos oscuros del magisterio eclesiástico. Barcelona: Herder.

GuITTON, Jean; Grichka e Igor Bogdanov. 1998. Dios y la ciencia. Hacia el metarrealismo. Cuarta Edición. Madrid: Debate.

KAUFFMANN DOIG, Federico. Encuentro de dos religions: la bíblica y la andina.

LACADENA, Juan Ramón y otros. 1984. En el centenario de Méndel: La genética ayer $y$ hoy. Madrid: Alambra.

LLINAS, Rodolfo R. 1993. El cerebro y el mito del yo. Bogotá: Norma.

LOTMAN, Iuri M. 1996-98. La semiosfera. Madrid: Catedrá. 2 tomos.

LYDON, Juan J. (Comp.). 1999. La inculturación: Teoría y práctica desde el carisma agustiniano latinoamericano. México: OALA.

MAILER, Norman. 1998. El Evangelio según el Hijo. Barcelona: Anagrama.

Maturana, Humberto y VARela, Francisco. 1990. El árbol del Conocimiento. Santiago de Chile: Debate.

-, Humberto y VARELA, Francisco. 1972-1980. De máquinas y seres vivos. Santiago de Chile: Universitaria.

Moltmann, Jürgen. 1993. El Camino de Jesucristo. Salamanca: Sígueme.

-, Jürgen. 1997. Dios en la Creación. Salamanca: Sígueme.

MORIN, Edgar. 1988-1993. El método. Madrid: Cátedra.

NiCOLIS, Gregoire, PRIGOGINE, Ilya. 1994. La estructura de lo complejo: En el camino hacia una nueva comprensión de las ciencias. Madrid: Alianza. 
ASETT. Por los muchos caminos de Dios. 2003. Quito: Centro Bíblico Verbo Divino. PRIGOGINE, I.1991. La nascita del tempo. Milao: Bompiani.

-, I. \& STENGERS. 1992. I. Entre o tempo e a eternidade São Paulo: Compania das Letras.

REEVES, Hubert. 1995. Últimas noticias del cosmos: Hacia el primer segundo. Santiago de Chile: Andrés Bello.

SOBERÓN MAINERO, Francisco Xavier. 1999. La ingeniería genética y la nueva biotecnología. México: Fondo de Cultura Económica.

StigLiTZ, Joseph E. 2003. El Malestar en la Globalización. Madrid. Punto de Lectura.

STORIG, Hans Joachim. 1997. Historia universal de la filosofía. Madrid: Ed. Tecnos, $2^{\mathrm{a}}$ ed. 808 pp.

ChARdin, Teilhard. 1976. Le coeur de la matiere. París: Editions du Seuil.

TreviJAno ETCheVerría, Manuel. 1996. Fe y ciencia: antropología. Salamanca: Sígueme.

VARgas LloSA, Mario. 1966. La utopía arcaica: José María Arguedas y las ficciones del indigenismo. México: Fondo de Cultura Económica.

VIDAL BENEITO, José, comp. 2003. Hacia una sociedad civil global. Madrid: TaurusUnesco. En este volumen están las citas referidas a Doudu Diène. 